http://jmscr.igmpublication.org/home/

ISSN (e)-2347-176x ISSN (p) 2455-0450

crossref DOI: https://dx.doi.org/10.18535/jmscr/v7i7.16

\title{
The Application of Steroid therapy along with wide Local Excision in the Treatment of Idiopathic Granulomatous Mastitis (IGM) in Private Hospital of Patuakhali
}

Authors

\author{
Dr Din Mohammad ${ }^{1}$, Dr Sami Ahmad ${ }^{2}$, Dr Proshanta Roy ${ }^{3}$ \\ ${ }^{1}$ MBBS, FCPS (Surgery), MRCS (UK), Associate Professor of Surgery, Patuakhali Medical College, \\ Patuakhali, Bangladesh \\ ${ }^{2}$ MBBS, FCPS (Surgery), Associate Professor of Surgery, Shaheed Suhrawardy Medical College, Dhaka, \\ Bangladesh \\ ${ }^{3}$ Assistant Professor, Surgery, Dhaka Community Medical College and Hospital, Dhaka, Bangladesh
}

\begin{abstract}
Background: Idiopathic granulomatous mastitis (IGM) is an unusual chronic inflammatory disease of the breast with undefined optimal treatment schedule.

Objective: In this study our main goal is to evaluate the application of steroid therapy along with wide local excision in the treatment of IGM.

Method: This retrospectively observational study was carried out Private Hospitals at Dhaka and Patuakhali from march 2016 to march 2017 where 30 GM patients characteristics, symptoms, results of the diagnostic workup, treatment, and outcome evaluated.

Result: during the study,71\% patients belonged to 25 to 34 years age range and focal homogeneous enhancing masses with irregular borders found in 5 cases. Also found $98.2 \%$ recovered initially after surgical excision with steroid treatment.

Conclusion: we can conclude that for GM excision along with systemic steroid therapy is superior to steroid therapy which provides strict diagnosis as well as much faster healing and less complications. Further study is needed for better outcome.

Keywords: Idiopathic granulomatous mastitis (IGM) chronic, Steroid treatment.
\end{abstract}

\section{Introduction}

Idiopathic Granulomatous mastitis (IGM) is a rare chronic inflammatory disease of the breast. Even though it is benign, its clinical and radiological features frequently mimic breast carcinoma. It may also be problematic to distinguish from infective mastitis and inflammatory breast disease of known etiology. The etiology of IGM is unidentified, but some authors have noted that the cause may be an autoimmune progression, unobserved microorganisms, use of oral contraceptives, or a response to childbirth. Granulomatous mastitis is categorized pathologically by the incidence of chronic granulomatous lobulitis in the absence of an obvious. Though the occurrence of IGM is 
increasing fast, only a few hundred cases have been described internationally. ${ }^{[1][2][3][4]}$

Patients typically present with a hard lump in one breast deprived of any sign of a systemic disease. Other possible symptoms comprise nipple retraction, pain, inflammation of the overlying skin, nipple discharge, fistula, enlarged lymph nodes.. Presentation is typically unilateral though a substantial share of cases is bilateral, also in many cases contralateral or bilateral recurrences were recognized. Numerous cases happening together with fever, polyarthralgia and erythema nodosum were known. ${ }^{[4][5]}$
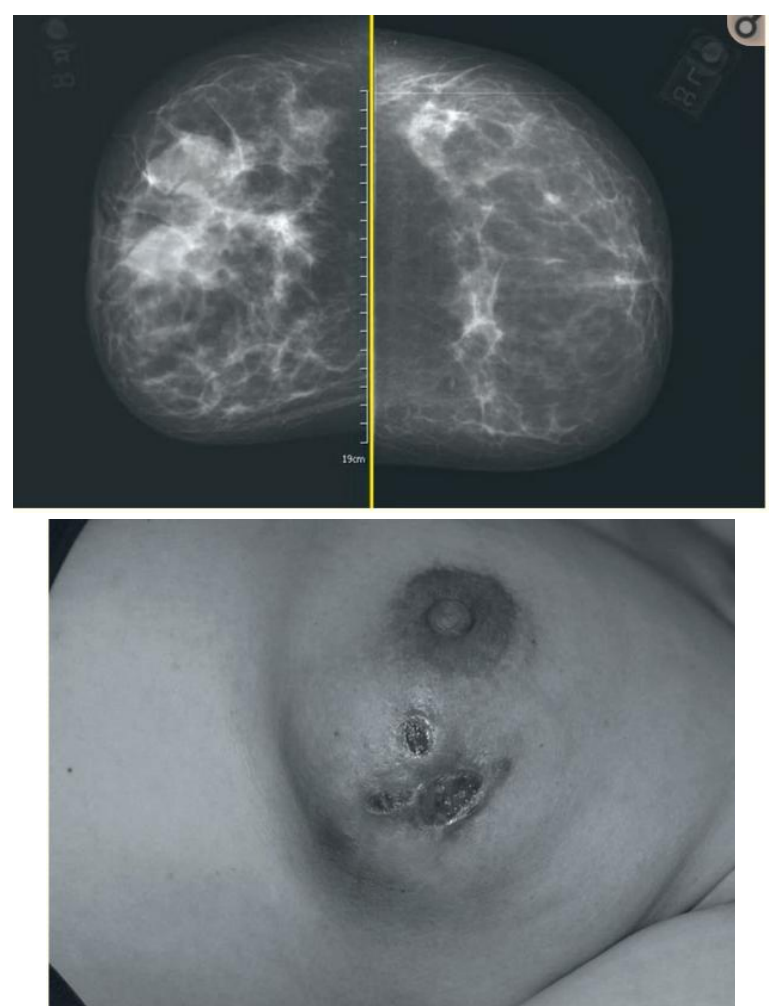

Figure-1a and1b: shows focal asymmetrical density with indistinct margins is seen in the retroareolar area of the right breast 30 years IGM patients and left breast in an IGM patient with fistula formation

To identify these autoimmune origins, serologic tests (rheumatoid factor and antinuclear antibody) can be performed although found negative in most reports. Ultrasonography (US) may be very helpful in the identifications of abscesses, but both US and mammography (MG) might be misleading in some reports of GM. In numerous studies magnetic resonance imaging (MRI) is acknowledged as a complementary diagnostic tool. ${ }^{[6][7]}$ Definitive analysis can only be done by histopathological examination of the diseased breast tissue. Suitable management is unknown but some surgical excision, or use of antibiotics, anti-inflammatory drugs, or corticosteroids have been projected. In this study we aimed is to estimate the application of steroid therapy along with wide local excision in the treatment of IGM

\section{Objective}

\section{General objective}

$>$ To estimate the application of steroid therapy along with wide local excision in the treatment of IGM

\section{Specific objective}

$>$ To observe lesions in different cases of the patients.

$>$ To evaluate treatment of the first attacks of IGM patients.

\section{Methodology \\ Study Type \\ $>$ This was a retrospectively observational study.}

\section{Study place and period}

$>$ In this study total of 30 cases with a histologically confirmed diagnosis of IGM treated from March 2016 to march 2017 at Private Hospitals at Dhaka and Patuakhali where retrospectively evaluated patient characteristics, symptoms, results of the diagnostic workup, treatment, and outcome.

\section{Method}

$>$ During the experiment pathological diagnosis of IGM with the observation of granulomatous inflammatory reaction in the breast lobules was made by core biopsy or surgical biopsy. After the first attack the mean follow-up period was 40.4 months (range 18-81 months) for recurrent cases and 25.2 months for IGM cases with a single attack. During the study we performed core biopsy or surgical biopsy, because using such biopsy the tissue is usually examined under a 
microscope by a pathologist and can also be analyzed chemically and also can determine whether a lesion is benign or malignant and also helpful to exclude other granulomatous mastitis cases from IGM one. Granulomatous mastitis secondary to different pathological causes was excluded on the basis of clinical and pathological criteria.

\section{Data analysis}

Data were collected in predesigned data collection sheet using various parameters. Interviews conducted using direct questionnaire and all information will be noted in pre from data collection sheet. Data were compiled and appropriate statistical package for social science (SPSS).

\section{Result}

In figure-2 shows age distribution of the patients where out of 30 patients $71 \%$ patients belonged to 25 to 34 years age range followed by $20 \%$ within 35 to 44 years and 9\% 45 and above. The following figure is given below in detail:

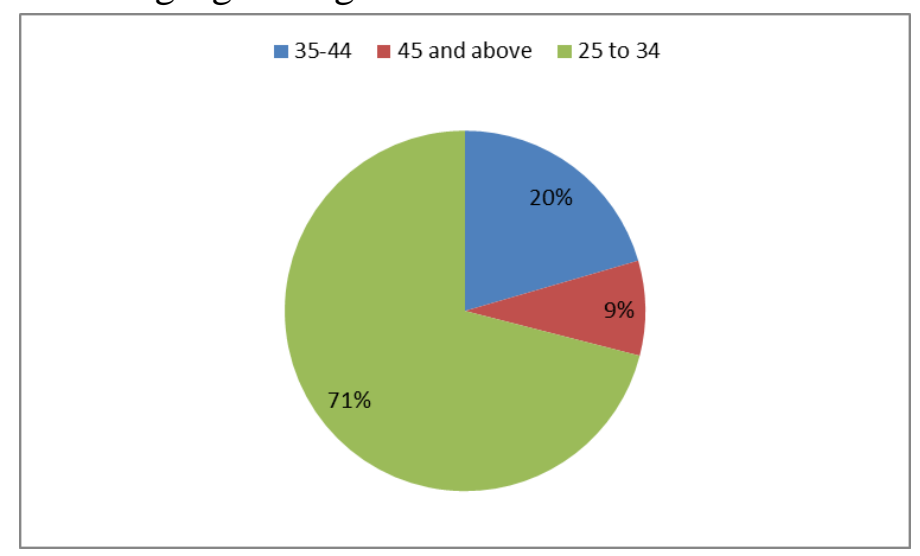

Figure-2: Age distribution of the patients.

In table-1 shows distribution of the patients according to complaints at presentation where the highest complaints at demonstration were a lump with or without overlying skin changes in 11 cases. The following table is given below in detail:

Table-1 Complaints at demonstration

\begin{tabular}{|l|c|}
\hline Cases & Frequency \\
\hline $\begin{array}{l}\text { Breast lump with or without overlying } \\
\text { Skin changes }\end{array}$ & 11 \\
\hline $\begin{array}{l}\text { Discomfort or breast pain and Nipple } \\
\text { retraction or discharge }\end{array}$ & 5 \\
\hline
\end{tabular}

\begin{tabular}{|l|c|}
\hline $\begin{array}{l}\text { History of incision and drainage of } \\
\text { breast abscess }\end{array}$ & 8 \\
\hline $\begin{array}{l}\text { Healing wounds with Recurrent abscess } \\
\text { formation }\end{array}$ & 6 \\
\hline Total & 30 \\
\hline
\end{tabular}

In table-2 shows lesions observation of the patients in different case where lesions were observed in the left breast in 16 cases $(53.33 \%)$ and in the right breast in 10 cases $(33.33 \%)$, while contralateral breast involvement in a relapse was detected in 4 case (13.33\%). The following table is given below in detail:

Table-2: Lesions observation of the patients in different case

\begin{tabular}{|l|c|c|}
\hline Variable & Frequency & $\%$ \\
\hline Left breast & 16 & $53.33 \%$ \\
\hline Right breast & 10 & $33.33 \%$ \\
\hline Contralateral breast & 4 & $13.33 \%$ \\
\hline
\end{tabular}

In figure-3 shows observational outcome of the patients after US examination where majority of the patients had inflammatory mastitis. The following figure is given below in detail:

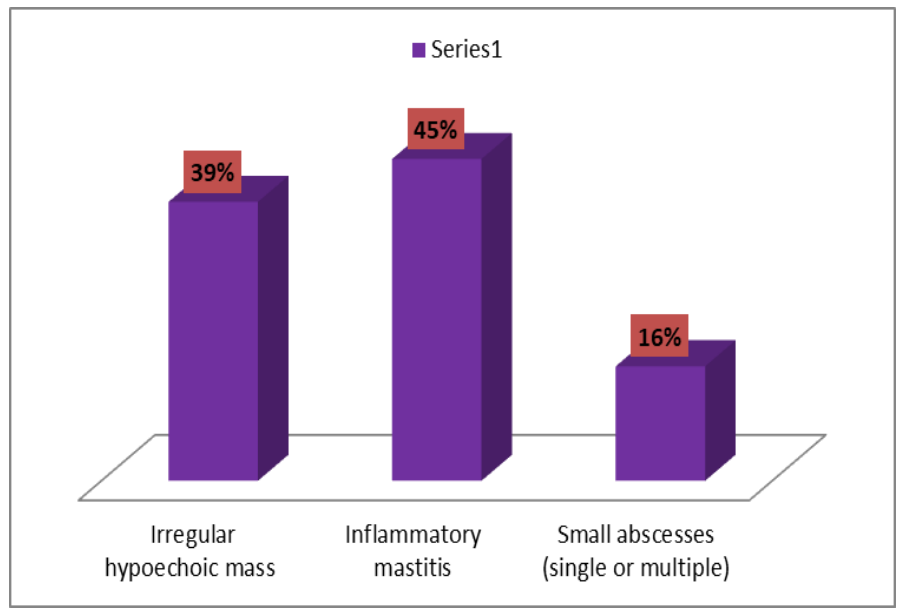

Figure-3: Observational outcome of the patients after US examination

In figure-4 shows pathological conclusions of the patients after MRI where focal homogeneous enhancing masses with irregular borders in 5 cases, inflammatory changes with parenchymal distortion in 4, and abscess formation in 3. The following figure is given below in detail: 


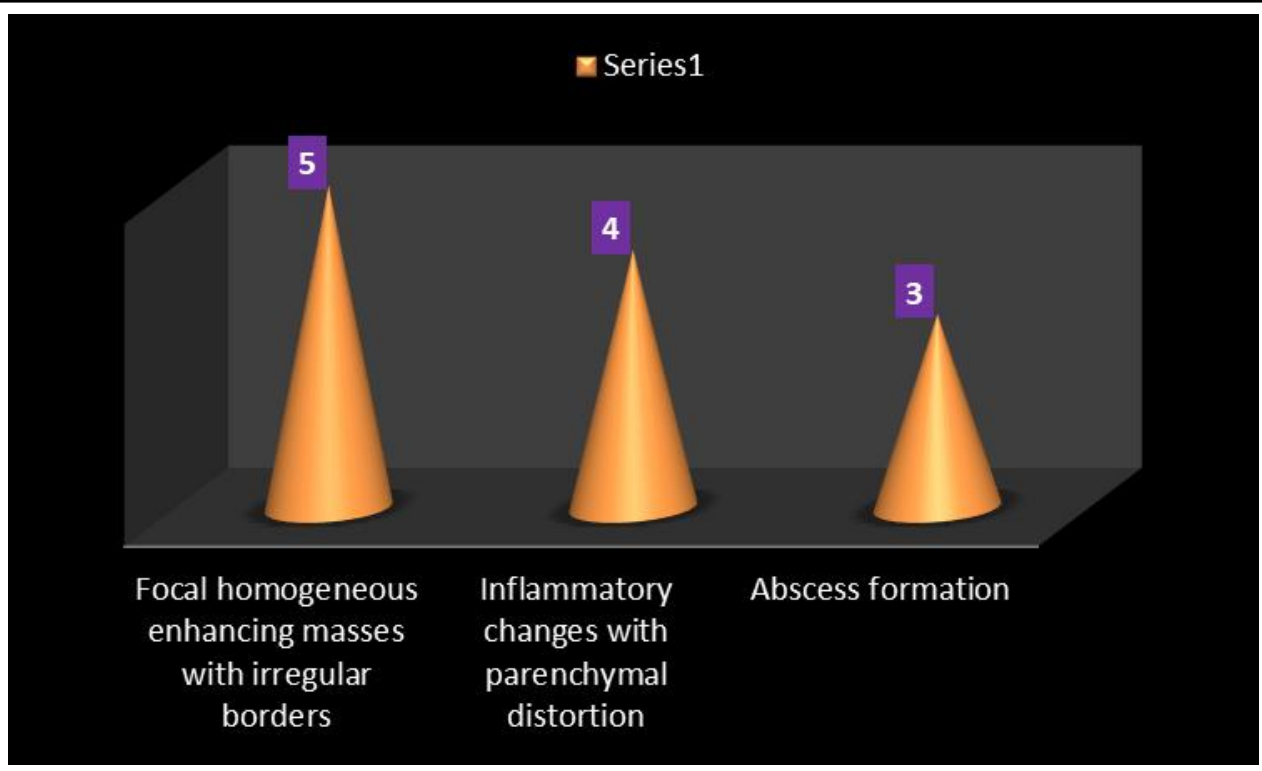

Figure-4: Pathological conclusionsof the patients after MRI.

In table-3 shows treatment methods used at first presentation of all IGM cases and their outcome where shows that abscess drainage with steroid therapy was performed whom had a relapse $43 \%$.
We also performed surgical excision with steroid and found $98.2 \%$ recovered initially and relapse rate only $17.9 \%$. The following table is given below in detail:

Table 3: Treatment methods used at first presentation of all idiopathic granulomatous mastitis cases and their outcome

\begin{tabular}{|l|c|c|c|c|}
\hline $\begin{array}{l}\text { Primary treatment } \\
\text { method }\end{array}$ & $\begin{array}{c}\text { Complete healing with } \\
\text { initial treatment, \% }\end{array}$ & $\begin{array}{c}\text { Excision required for } \\
\text { complete healing, \% }\end{array}$ & $\begin{array}{c}\text { Recurrence after } \\
\text { complete healing, \% }\end{array}$ & $\begin{array}{c}\text { Mean follow-up, } \\
\text { months }\end{array}$ \\
\hline Systemic steroid therapy & $42 \%$ & $58 \%$ & $41.45 \%$ & 36 \\
\hline $\begin{array}{l}\text { Abscess drainage with } \\
\text { Steroid therapy }\end{array}$ & $57 \%$ & $43 \%$ & $40.65 \%$ & 36 \\
\hline $\begin{array}{l}\text { Surgical excision with } \\
\text { Steroid therapy }\end{array}$ & $98.2 \%$ & $1.8 \%$ & $17.9 \%$ & 36 \\
\hline
\end{tabular}

In figure-5 shows treatment of the first attacks of idiopathic granulomatous mastitis in recurrent cases where disease recurrence was observed in 6 patients among them abscess drainage cases were disease free interval 5 mean months but for surgical excision was disease free interval average 15 months. The following figure is given below in detail:

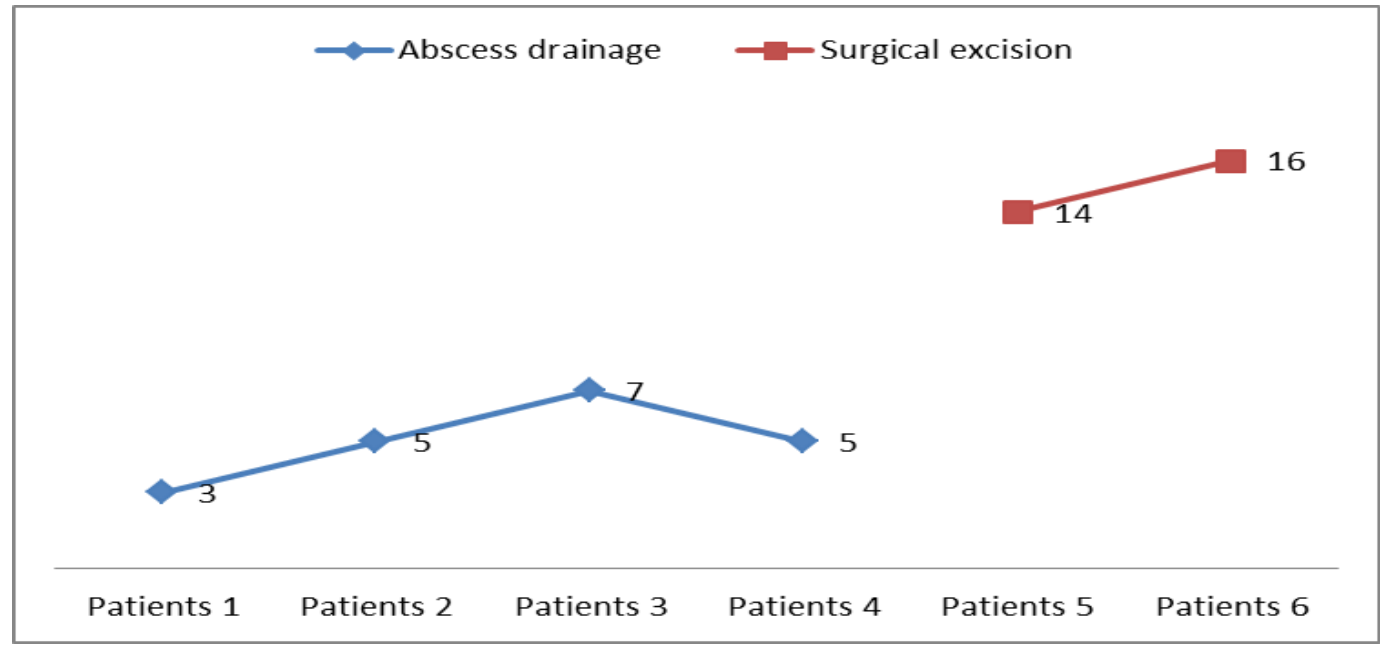

Figure 5: Treatment of the first attacks of Idiopathic granulomatous mastitis in recurrent cases 


\section{Discussion}

IGM is a chronic benign disease and no clear etiology is found till now. In 1972 it was first described as an entity by Kessler and Wolloch. ${ }^{[1]}$. Many agents such as local irritants, viruses, mycotic and parasitic infections, hyperprolactinemia, diabetes mellitus, breast trauma, oral contraceptive use, and smoking have been considered for IGM occurrence, but an autoimmune reaction is favored in some cases.

IGM is a rare disease, instituting $24 \%$ of all breast inflammatory disease. ${ }^{[8]}$ It involves a prolonged course of treatment and follow-up as it is usually related with recurrence. Although no ethnic predisposition was described. Most patients with IGM are of reproductive age but older women can also be affected by it. ${ }^{[6][9][10]}$

During the study we found that $71 \%$ patients belonged to 25 to 34 years age range followed by $20 \%$ within 35 to 44 years and $9 \% 45$ and above. This is quiet similar to other study. One study reported that the median age of the patients was 33 years. ${ }^{[1][2]}$

In our study, 39\% patients had a hypoechoic irregular mass on US were managed with excision. All of them had pathological IMG findings of asymmetric density or an ill-defined nodule. Conclusive diagnosis can only be made by histopathological examination of the breast lesion. However cytological structures, detected especially in the material obtained by needle biopsy, may sometimes make it difficult to differentiate IGM from other granulomatous diseases of the breast and from carcinoma. ${ }^{[6][11[12]}$

In the past, false-positive needle biopsies resulted in unnecessary mastectomies. ${ }^{[13[14]}$ In this study in all cases we did core biopsy or open surgical biopsy and obtained a correct diagnosis of IGM in all patients. Chest X-ray, tuberculin skin test, determination of erythrocyte sedimentation rate, and PCR may also help with the analysis to exclude tuberculosis. ${ }^{[15][16]}$

Treatment of IGM is debatable, but use of antibiotics or corticosteroids and wide excision of the affected tissue have all been measured.
Antibiotic use is debatable as most IGM cases are either sterile or infected with unnoticed microorganisms. It offers a conclusive diagnosis, causes few side effects, and cures the patient more quickly with observation of fewer recurrences. But some articles reported that wide excision in the presence of mastitis is associated with delayed wound healing with subsequent disease recurrence and poor cosmetic outcome.

Conversely excision is usually done because of discrepancies between needle biopsy outcomes and clinical findings. It was noted that more than $50 \%$ of IGM cases were primarily misdiagnosed as carcinoma. In our study abscess drainage with steroid therapy was performed whom had a relapse $43 \%$. We also performed surgical excision with steroid and found $98.2 \%$ recovered initially and relapse rate only $17.9 \%$.

Some authors recommend that re-excision upon recurrence, however discordance between the size of the lesion and that of the breast does not always allow re-excision. ${ }^{[6]}$ In this study single relapse detected after healing with surgical excision, we also done re-excision as the breast size was adequate.

After abscess drainage or steroid therapy relapses were also treated with surgical excision for fear of an underlying missed malignancy. On the other hand, steroid therapy was described to decrease the size of the lesion and provide complete healing only when used long-term. ${ }^{[6]}$

It is not feasible to do abscess drainage alone in the treatment of IGM as there is high recurrence rate. It may be better to do wide excision instead of abscess drainage or to continue with steroid therapy following the drainage procedure because most abscesses in IGM are multilocular. The recommended primary dose of prednisolone in advanced disease is $0.8 \mathrm{mg} / \mathrm{kg} /$ day in divided doses, provided the lesion is sterile. ${ }^{[17]}$ It is typically continued in low doses for at least 6 weeks till a complete clinical response is observed. In the literature the recurrence rate of IGM is reported to be $16-50 \%$ even if complete resolution is obtained. ${ }^{[12]}$ 


\section{Conclusion}

From the result, we can conclude that excision along with systemic steroid therapy is superior to steroid therapy with or without abscess drainage provides a strict diagnosis as well as much faster healing and less complications.

\section{Reference}

1. Kessler E, Wolloch Y. Granulomatous mastitis: a lesion clinically simulating carcinoma. Am J ClinPathol. 1972;58:642646.

2. Erhan Y, Veral A, Kara E, Ozdemir N, Kapkac M, Ozdedeli E, et al. A clinicopathologic study of a rare clinical entity mimicking breast carcinoma: idiopathic granulomatous mastitis. Breast. 2000;9:5256.

3. Asoglu O, Ozmen V, Karanlik H, Tunaci M, Cabioglu N, Igci A, et al. Feasibility of surgical management in patients with granulomatous mastitis. Breast J. 2005;11:108-114.

4. Cohen C. Granulomatous mastitis. A review of 5 cases. S Afr Med J. 1977;52:14-16.

5. Akcan, Alper, A. BahadırÖz, SerapDogan, HülyaAkgün, MuhammetAkyüz, Engin Ok, Mustafa Gök, and TutkunTalih. "Idiopathic granulomatous mastitis: comparison of wide local excision with or without corticosteroid therapy." Breast Care 9, no. 2 (2014): 111111.

6. Akcan A, Akyildiz H, Deneme MA, Akgun $\mathrm{H}$, Aritas Y: Granulomatous lobular mastitis: a complex diagnostic and therapeutic problem. World J Surg 2006;30:1403-1409.

7. Tuncbilek N, Karakas HM, Otken OO: Imaging of granulomatous mastitis: assessment of three cases. Breast 2004;13:510-514.

8. Diesing $\mathrm{D}$, Axt-Fliedner R, Hornung $\mathrm{D}$, Weiss JM, Diedrich K, Friedrich M:
Granulomatous mastitis. Arch GynecolObstet 2004;269:233-236.

9. Lai EC, Chan WC, Ma TK, Tang AP, Poon CS, Leong HT: The role of conservative treatment in idiopathic granulomatous mastitis. Breast J 2005;11:454-456.

10. Erhan Y, Veral A, Kara E, Ozdemir N, Kapkac M, Ozdedeli E, Yilmaz R, Koyuncu A, Erhan Y, Ozbal O: A clinicopathologic study of a rare clinical entity mimicking breast carcinoma: idiopathic granulomatous mastitis. Breast 2000;9:52-56

11. Asoglu O, Ozmen V, Karanlik H, Tunaci M, Cabioglu N, Igci A, Selcuk UE, Kecer M: Feasibility of surgical management in patients with granulomatous mastitis. Breast $\mathrm{J}$ 2005;11:108-114.

12. Heer R, Shrimankar J, Griffith CD: Granulomatous mastitis can mimic breast cancer on clinical, radiological or cytological examination: a cautionary tale. Breast 2003;12:283-286.

13. Imoto $\mathrm{S}$, Kitaya $\mathrm{T}$, Kodama $\mathrm{T}$, Hasebe $\mathrm{T}$, Mukai K: Idiopathic granulomatous mastitis: case report and review of the literature. Jpn J ClinOncol 1997;27:274-277

14. Bani-Hani KE, Yaghan RJ, Matalka II, Shatnawi NJ: Idiopathic granulomatous mastitis: time to avoid unnecessary mastectomies. Breast J 2004;10:318-322.

15. Harris SH, Khan MA, Khan R, Haque F, Syed A, Ansari MM: Mammary tuberculosis: analysis of thirty-eight patients. ANZ J Surg 2006;76:234-7.

16. Sriram K, Moffatt D, Stapledon R: Tuberculosis infection of the breast mistaken for granulomatous mastitis: a case report. Cases J 2008;1:273

17. Tuli R, O’Hara BJ, Hines J, Rosenberg AL: Idiopathic granulomatous mastitis masquerading as carcinoma of the breast: a case report and review of the literature. IntSeminSurgOncol 2007;4:21. 